\title{
Solid Carbon Produced in an Inductively Coupled Plasma Torch with a Titan Like Atmosphere
}

\author{
D. Vacher, ${ }^{1}$ S. Menecier, ${ }^{2}$ M. Dudeck, ${ }^{3}$ M. Dubois, ${ }^{4}$ B. Devouard, ${ }^{5}$ and E. Petit ${ }^{4}$ \\ ${ }^{1}$ Clermont Université, Université d'Auvergne, LAEPT, BP 10448, 63000 Clermont-Ferrand, France \\ ${ }^{2}$ Clermont Université, Université Blaise Pascal, LAEPT, BP 10448, 63000 Clermont-Ferrand, France \\ ${ }^{3}$ Institut Jean Le Rond d'Alembert, Université Pierre et Marie Curie (Paris 6), 75252 Paris, France \\ ${ }^{4}$ Laboratoire des Matériaux Inorganiques (LMI), CNRS, UMR6002, Université Blaise Pascal, Clermont-Ferrand II, Clermont \\ Université, Ecole Nationale Supérieure de Chimie de Clermont-Ferrand, 63000 Clermont-Ferrand, France \\ ${ }^{5}$ Laboratoire Magmas et Volcans, UMR6524, CNRS, Université Blaise Pascal, Clermont Université, 63000 Clermont-Ferrand, France
}

Correspondence should be addressed to D. Vacher; damien.vacher@univ-bpclermont.fr

Received 11 February 2013; Accepted 27 May 2013

Academic Editor: Mahmut Reyhanoglu

Copyright (C) 2013 D. Vacher et al. This is an open access article distributed under the Creative Commons Attribution License, which permits unrestricted use, distribution, and reproduction in any medium, provided the original work is properly cited.

Solid carbon is deposited on the surfaces of an inductively coupled plasma torch operating with a Titan like atmosphere plasma gas. The frame of the initial research is the study of the radiative properties of plasma encountered around a spacecraft during its hypersonic entry in upper layers of planetary atmosphere. Deposition of carbon is observed not only on the quartz tube outside the inductor but also on the ceramic protection of the torch injector. Carbon exhibits two types of morphology more or less dense and it is analyzed by various analytic devices as MEB, SEM, TEM, EDS and Raman spectroscopy. The gathered carbon powder shows the presence of nanostructured particles.

\section{Introduction}

The atmospheric entry of a spacecraft is a critical phase for the success of a planet exploration, and an efficient thermal protection system (TPS) is required to protect the probe against the energy surface flux. For a high velocity entry $\left(>11 \mathrm{~km} \cdot \mathrm{s}^{-1}\right)$ in the upper layers of the atmosphere of the planet, the radiative flux of energy issued from the plasma created in the shock layer is predominant compared to convective flux (up to ten times more). New materials are currently studied to increase the protection without negative effect on the mass of the probe as phenolic materials $[1,2]$. As a consequence, the study of radiative properties of such plasmas (formed with Earth, Mars, or Titan atmospheres) is required to optimize the size (thickness, mass) of the TPS (front shield and back shield).

In order to simulate the radiative properties of the encountered plasmas during an atmospheric entry, various experimental devices are used as shock tubes, arc jets, microwave plasmas, and inductively or capacitively coupled plasma torches [3]. From these devices, various entry configurations, in terms of pressure and velocity by shock tubes, nonequilibrium of ionization, and radiative processes by the other facilities, can be studied.

The study of Titan, Saturn's largest moon, is of great scientific interest due to some similarities with the Earth discovered by the NASA's Cassini spacecraft (2004) as seasonal and daily changes, clouds, winds, and surface aspects [4] but with a lower surface temperature $(<100 \mathrm{~K})$. Its thick atmosphere is mainly composed of nitrogen and methane with traces of ammonia, argon and carbon dioxide, propane, and ethane and could host preliminary elements of microbiological life. Thus, to prepare new missions of Titan exploration, the radiative properties of a Titan-like atmosphere plasma (98\% $\mathrm{N}_{2}-2 \% \mathrm{CH}_{4}$ ) have been investigated to deepen the knowledge of the energy flux toward the surface of a spacecraft. With this objective, the LAEPT uses an inductively coupled plasma (ICP) torch working at atmospheric pressure and at a maximal applied power of $4 \mathrm{~kW}$. The atmospheric pressure ensures that the plasma is at thermal and chemical 
equilibrium and the spectroscopic measurements realized are then very useful for radiative models validation.

Molecular spectra with carbon $\mathrm{CN}(\Delta v=0), \mathrm{CN}(\Delta v=$ $-1)$, and $C_{2}$ Swann system $(\Delta \nu=0)$ are observed by an optical emission spectrometer and the recorded spectra allow the determination of a temperature by comparison with numerical simulation. Atomic line of $\mathrm{C}$ is registered at $247 \mathrm{~nm}$. At equilibrium conditions, the densities of $\mathrm{CN}$ and $\mathrm{C}_{2}$ exhibit a maximum value for a temperature around $4000 \mathrm{~K}$ but the concentration of $\mathrm{CN}$ is always $10^{2}$ greater than the concentration of $\mathrm{C}_{2}$. The atomic carbon $\mathrm{C}$ concentration is the main species after $4500 \mathrm{~K}$. A Mach-Zehnder interferometer has been also used for the determination of the temperature. Related papers are already available on these topics $[5,6]$. In previous experiences [5], it was shown that Titan-like plasmas in our ICP plasma torch contain solid carbon, as provided by the thermodynamical calculations in equilibrium conditions. It must be noted that a lot of articles are available concerning the formation of tholins (mixed compounds of $\mathrm{H}, \mathrm{C}$, and N) [7-12] in this kind of plasmas, which are generally sustained at lower pressure and lower enthalpy but it is rarer to observe pure carbon. Other plasma processes show the formation of black carbons from decomposition of methane [13-15].

This present paper gives the properties of the gathered solid carbon at the surface of the injector and onto the quartz tube. The outline of the paper is as follows. After the presentation of facilities in Section 2, the carbonaceous products, which are deposited both at the top of the auxiliary alumina injector and on different areas of the ICP quartz tube, are characterized using Raman diffusion spectroscopy, Energy-dispersive X-ray spectroscopy (EDS), scanning, and transmission electron microscopy (SEM and TEM resp.) in Section 3 .

\section{Experimental Setup and Analytical Devices}

2.1. ICP-T64 Torch. The inductively coupled plasma torch ICP-T64 can operate with different plasma gas (air, argon, $\mathrm{CO}_{2}, \mathrm{~N}_{2}$, and gas mixtures). A seven-turn induction coil, made in inconel, cooled by an inner air flow is used to sustain the Titan-like atmosphere plasma. Figure 1 shows two photos and a scheme of the experimental setup.

At atmospheric pressure, the plasma formed inside the ICP torch is ignited by a metallic wire (Inox steel) plunged into the quartz tube. Once the first electrons are ejected into the plasma gas, they are accelerated by the electromagnetic field and it can shock with the other particles. So, the plasma is ignited and it is sustained by the power delivering at the inductor. The operating conditions of the experimental setup are given in Table 1.

The plasma is generated through the induction coil by a radio frequency $(\mathrm{RF})$ of $64 \mathrm{MHz}$ at an electrical applied power of up to $4 \mathrm{~kW}$. The plasma is confined within a $28 \mathrm{~mm}$ wide cylindrical, vertically mounted quartz tube. The plasma gas, with a swirl injection, has a fixed total mass flow rate of $0.2 \mathrm{~g} \cdot \mathrm{s}^{-1}$.

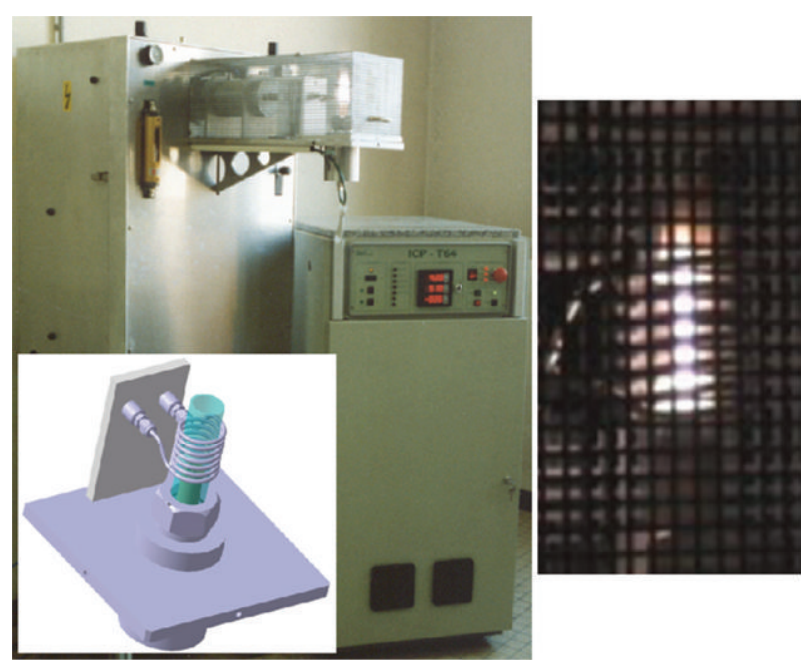

FIGURE 1: Experimental setup and photo of the plasma formed with a Titan-like atmosphere.

TABLE 1: Nominal operating conditions of the plasma torch setup.

\begin{tabular}{lc}
\hline Applied voltage & $4.57 \mathrm{kV}$ \\
Anode current & $460 \mathrm{~mA}$ \\
Power supply & $2.1 \mathrm{~kW}$ \\
Plasma gas flow rate & $0.2 \mathrm{~g} \cdot \mathrm{s}^{-1}$ \\
Operating pressure & Atmospheric pressure \\
\hline
\end{tabular}

2.2. Characterization of the Solid Carbon. The different samples of gathered carbon were analyzed by scanning and transmission electron microscopy (SEM, TEM) and by Raman diffusion.

2.2.1. SEM, EDS, and TEM. The SEM analysis is performed by a ZEISS Supra operating at $3 \mathrm{kV}$ and it is coupled with a Silicium Xmax EDS (Energy Dispersive Microscopy) system and INCA Energy 350 software. TEM was achieved using JEOL JEM 3010 microscope, with an accelerating voltage from 100 to $300 \mathrm{kV}$.

2.2.2. Raman. A Jobin Yvon T64000 microspectrometer with a charge coupled device multichannel detector has been used at room temperature to record the Raman spectra (Stokes lines). It works in the visible radiation range with an excitation source emitting at $\lambda=514.5 \mathrm{~nm}$ (Ar laser line) and with an incident power around $10 \mathrm{~mW}$ on a thin surface of a few $\mu \mathrm{m}^{2}$.

Raman analysis is known to be one of the most efficient techniques to investigate about bonds properties of carbon [16]. Indeed, carbon can exhibit miscellaneous bonds, corresponding to three hybridization states: $\mathrm{sp}^{1}, \mathrm{sp}^{2}$, and $\mathrm{sp}^{3}$ (carbon with only $\mathrm{sp}^{3}$ bonds is diamond, graphite if it has only $\mathrm{sp}^{2}$ bonds). Carbon properties depend mainly on its bonds nature. Very detailed explanations about Raman analyses of carbon can be found in Robertson papers ([16] for instance). Raman theory shows that the bonds properties of carbon can be derivated from two particular bands in 
the carbon Raman spectrum, the D-band (D for Disordered, nonvisible in pure graphite carbon [17]) and the G-band (G for Graphite). Indeed, the $G$ bands central position and the ratio of those bands surfaces, fitted with relevant models, allow to determine the percentage of $\mathrm{sp}^{3}$ and $\mathrm{sp}^{2}$ bonds into the carbon sample as shown in Figure 2.

Raman spectra were treated using a specific Matlab code developed at the LAEPT laboratory. This code allows to substract continuous signal and to fit $D$ and $G$ bands of amorphous carbon with, respectively, a lorentzian and BreitWigner-Fano (BWF) lineshape [16]. An example of such a fitting after background removing is presented in Figure 3 .

The ratio of $\mathrm{D}$ and $\mathrm{G}$ bands surfaces $I(\mathrm{D}) / I(\mathrm{G})$ is then calculated. The in-plane correlation length $L_{a}$ is also calculated using relation (1) [18]:

$$
L_{a}=\frac{c_{0}+c_{1} \cdot \lambda}{I(\mathrm{D}) / I(\mathrm{G})},
$$

with $\lambda$ (in nm), $c_{0}=-12.6 \mathrm{~nm}$, and $c_{1}=0.033$.

The in-plane correlation length can be defined as the scale length where even amorphous materials exhibit a periodic structure. That is why, in material science, even globally amorphous materials can be called nanostructured materials (or low crystalline order materials), depending on this inplane correlation plane.

\section{Analysis of Solid Carbon}

Figure 4 presents the localization of the carbon powder on the ceramic injector and on the quartz tube. The influence of the swirl injection of the plasma gas can be observed through the deposition shape on the inner surface of the quartz tube. It can be noted that no deposition occurs on the part of the tube located inside the seven turn induction coils where the plasma temperature is the highest. Since the melting point of the quartz is around $1920 \mathrm{~K}$, the presence of carbon powder must be discussed in terms of the plasma temperature distribution along the quartz tube. On the other hand, a deposition on the ceramic protection surrounding the auxiliary torch injector is observed and Figure 4 shows that the macroscopic shape seems radically different. It has to be noted that this auxiliary injector is not used for the plasma gas injection but it can be used to inject nebulized solutions inside the plasma gas. The ceramic protection plays two roles: the first one concerns the protection of the auxiliary injector and the second one allows to have a secondary guide of the plasma gas to ensure a cooling of the quartz tube.

3.1. Powder on the Ceramic. Whatever the sample collected, Raman spectrum recorded with an excitation wavelength of $514 \mathrm{~nm}$ (Figure 3 as a representative example) shows two broad lines in the $1300-1600 \mathrm{~cm}^{-1}$ range. The first line, centered at $1354 \mathrm{~cm}^{-1}$ and called D-band, is a forbidden mode due to symmetry in perfect graphite but is activated only in the presence of structural disorder. Its intensity is directly dependent on the presence of sixfold aromatic rings and is a good parameter of the disorder degree in carbon [19].
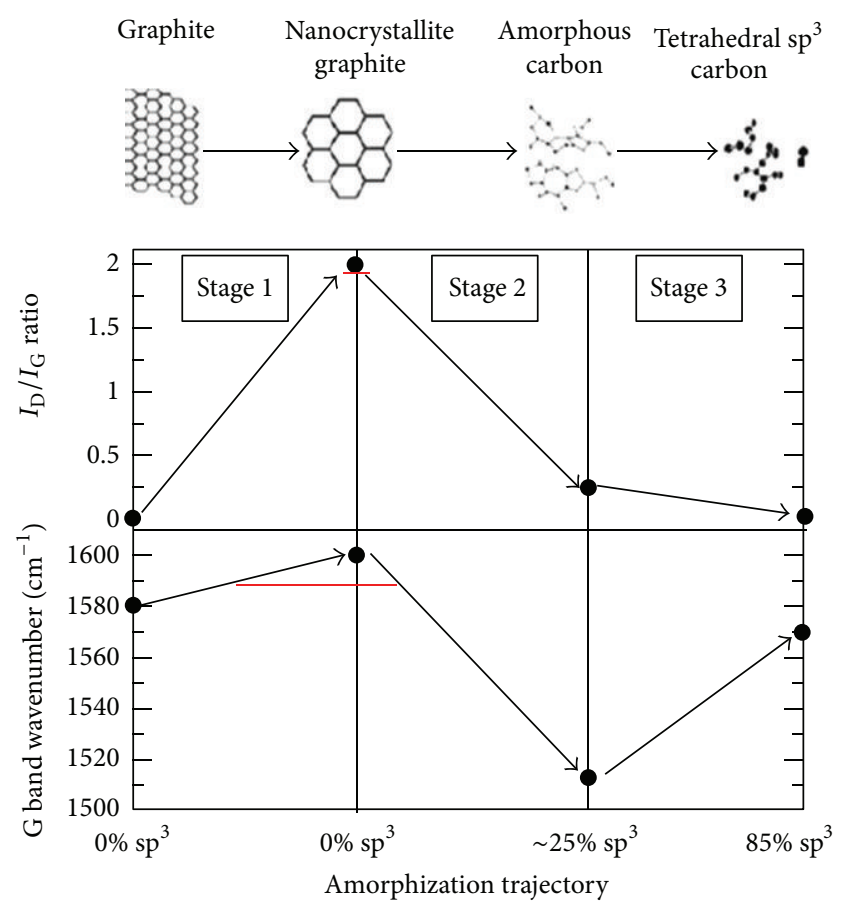

FIgURE 2: Ferrari-Robertson classification with three stages model.

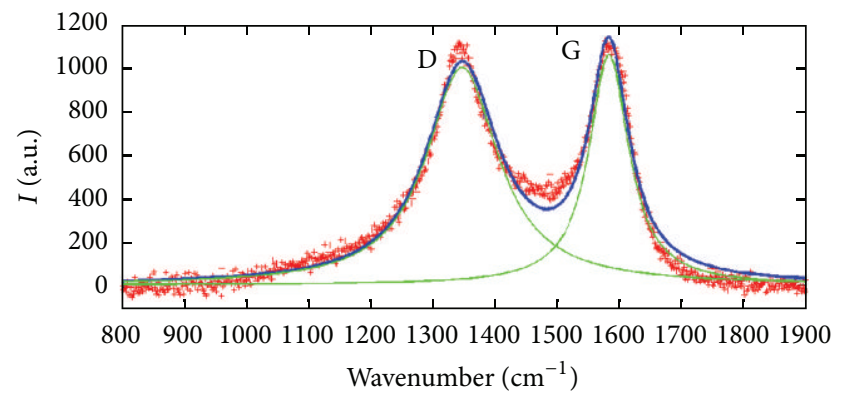

FIGURE 3: Example of a Raman spectrum obtained with quartz tube carbon and fitted with lorentzian (D) and BWF lineshape (G).

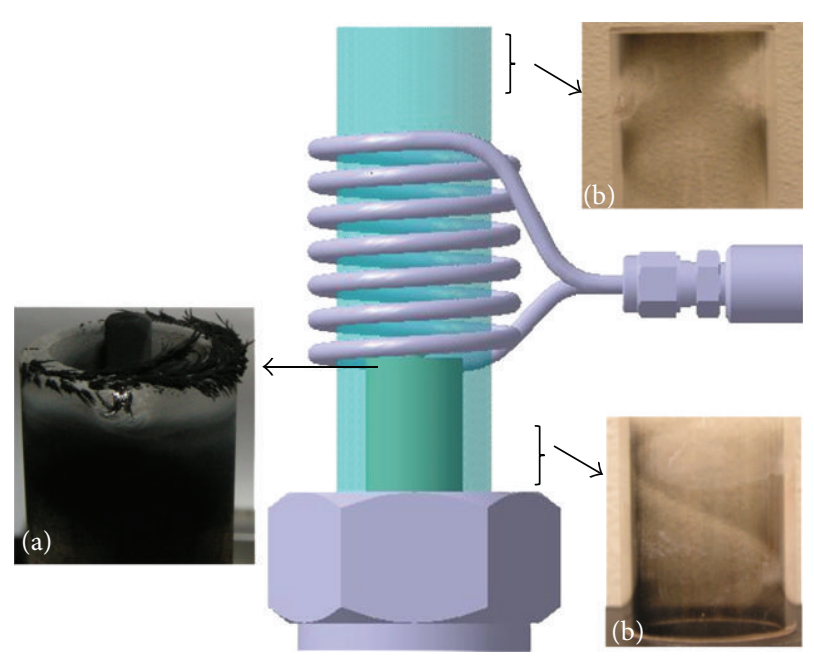

Figure 4: Powders location on the ceramic protection (a) and on quartz tube (b). 
The width of the D-band is correlated to a distribution of $\mathrm{sp}^{2}$ bonds clusters with different ring sizes.

The G-band at $1585 \mathrm{~cm}^{-1}$ appears due to in-plane bonds stretching of $\mathrm{sp}^{2}$ carbon pairs. The G-band width can be used as a measure of the order within the graphene planes [17] and a broadening of this band can be interpreted as an increase in bonds angle disorder. Robertson and Ferrari [16, 17, 19, 20] have discussed how the afore mentioned band parameters mentioned above can be used to describe the structure of carbon materials; three stages have been identified depending on the disorder in the carbon structure (Figure 2) characterized by the carbon hybridization. By reporting the results of our studied samples, that is, $I(D) / I(G)$ equal to 1.94 and $L_{a}=2.27 \mathrm{~nm}$, on this classification (Figure 2), this allows the carbonaceous materials to be classified as mainly $\mathrm{sp}^{2}$ carbon atoms with low coherency.

TEM observations confirmed the low crystalline order of the products. The particles are nearly spherical particles with an average diameter of $150 \mathrm{~nm}$. Two populations coexist with different disorder degrees. The small graphitic parts are differently dispersed. Some particles exhibit a higher organization close to the particles surface (Figures 5(d) and $5(\mathrm{e})$ ).

Electron diffraction pattern (Figure 5(g)) underlines well-defined rings in accordance with low crystalline order. The estimated interlayer distance is $0.35 \pm 0.01 \mathrm{~nm}$. At this step, the carbonaceous materials exhibit similarities with amorphous carbon blacks [21]. Such claim is confirmed by SEM observations (Figure 5). It shows elongated structures with a few hundred micrometers length. Those elongated morphologies can be sorted out in two different structures, rough and smooth. Several magnifications underline that the objects are made with agglomerates of smaller spherical particles, 50 to $150 \mathrm{~nm}$ sized.

Differences appear concerning the size of those particles in the two populations. In one case, the size is around $50 \mathrm{~nm}$ and their agglomeration forms a high surface area (Figure 6). In the second case, the particles form a sintering-like structure with grains of about $500 \mathrm{~nm}$ diameter (Figure 7).

Energy dispersive X-ray analysis, calibrated with two samples of SiCN thin films with defined amount of nitrogen (10 and 20 atomic \% from Rutherford back scattering measurements) shows that, contrary to tholins, the sample does not contain nitrogen whatever their morphology is (Figure 8). Only carbon was detected (aluminium peak is due to the SEM support), with no nitrogen.

3.2. Quartz Tube Powder. After experiments, carbon powder covered two different areas of the ICP quartz tube as shown in Figure 4. It is quite understandable that carbon condensation depends on the quartz temperature, in accordance with thermodynamic calculation for equilibrium conditions. The powders gathered at the top and at the bottom of the quartz tube were analyzed with TEM. TEM observations of the top quartz tube powder and the bottom quartz tube powder are presented in Figure 9. Structures of both powders are comparable to the high surface area structure found on the auxiliary injector, which tends to ensure that those structures are due to
TABLE 2: Raman spectroscopy results from the quartz tube powder.

\begin{tabular}{lccc}
\hline Height $(\mathrm{mm})$ & $\mathrm{G}$ position $\left(\mathrm{cm}^{-1}\right)$ & $I(\mathrm{D}) / I(\mathrm{G})$ & $L_{a}(\mathrm{~mm})$ \\
\hline 0 & 1594 & 2.23 & 1.96 \\
0 & 1593 & 1.90 & 2.30 \\
0 & 1591 & 2.30 & 1.90 \\
4 & 1591 & 2.11 & 2.07 \\
4 & 1592 & 2.19 & 1.99 \\
4 & 1590 & 2.29 & 1.91 \\
8 & 1594 & 2.19 & 2.00 \\
8 & 1592 & 2.17 & 2.02 \\
8 & 1590 & 2.14 & 2.05 \\
14 & 1590 & 1.34 & 3.27 \\
14 & 1590 & 2.20 & 1.99 \\
14 & 1592 & 2.00 & 2.19 \\
20 & 1593 & 2.03 & 2.16 \\
20 & 1593 & 2.04 & 2.15 \\
20 & 1592 & 2.10 & 2.08 \\
\hline
\end{tabular}

a vapor condensation process. The size of individual particles is around $50 \mathrm{~nm}$. The spaces between particles result in high porosity. While there is not any difference between the size of the individual particle, it seems that the carbonaceous material formed at the bottom of the quartz tube is less dense and more porous. Here again, whatever the sample is, EDS analyses underline the absence of nitrogen within the detection limit of the detector.

Raman spectroscopy analyses of carbon powders have been realized three times at different heights on the quartz tube (all in the upper area of quartz covered of powder). $I(\mathrm{D}) / I(\mathrm{G})$ ratios and corresponding $L_{a}$ are presented in Table 2 . These results show that variation of $I(\mathrm{D}) / I(\mathrm{G})$ and $L_{a}$ is not significative even at different heights. Thus, an average global result can be advanced:

$$
\begin{gathered}
\frac{I(\mathrm{D})}{I(\mathrm{G})}=2.08 \pm 0.17, \\
L_{a}=2.13 \pm 0.24 \mathrm{~nm} .
\end{gathered}
$$

Uncertainties were calculated using Student's method for a $99 \%$ confidence interval. Those values and average value of $\mathrm{G}$ band position are typical of a nanocrystallites of graphite with no $\mathrm{sp}^{3}$ bonds [16].

\section{Conclusion}

ICP plasma torch is a very convenient tool for the simulation of the plasma flow surrounding a spacecraft during its cross of the upper layers of a planetary atmosphere. For Titanlike atmosphere, the ICP-T64 inductively coupled plasma torch has been used to analyze the radiative properties of the plasma surrounding a spacecraft crossing the atmosphere of Titan (satellite of Saturn). In the ICP-T64 facility, the presence of depositions of solid carbon on the surfaces has been observed. The gathered carbon on the inner surface of the quartz tube and also on the ceramic protection of the auxiliary injector has been studied by means of different microscopic analyzers (Raman diffusion, SEM, TEM, and EDS). A high disorder degree of the carbonaceous materials 


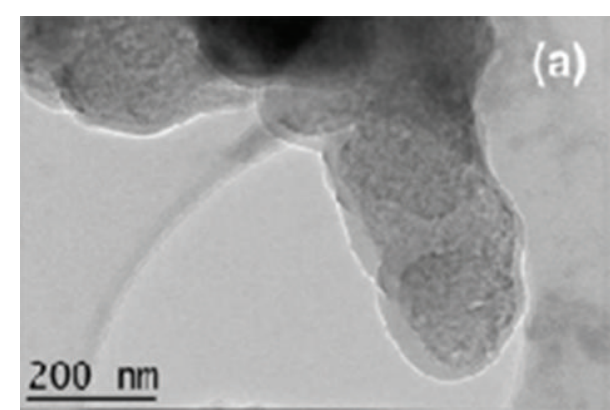

(a)

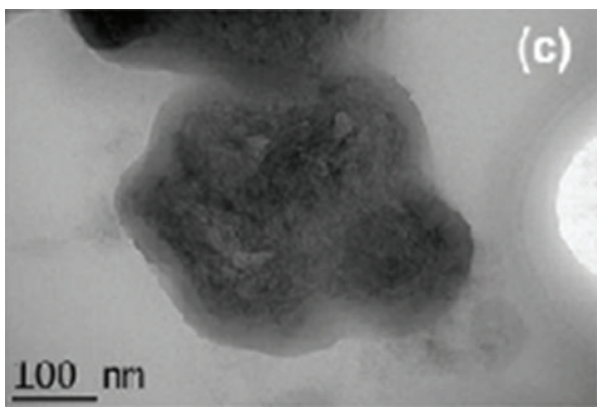

(c)

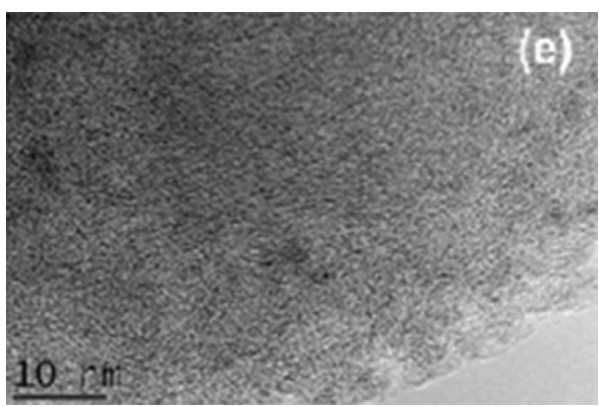

(e)

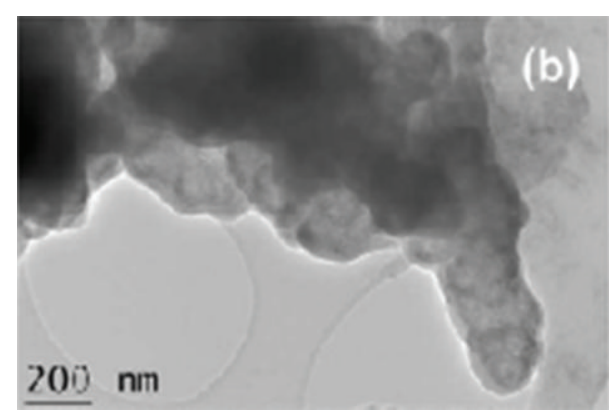

(b)

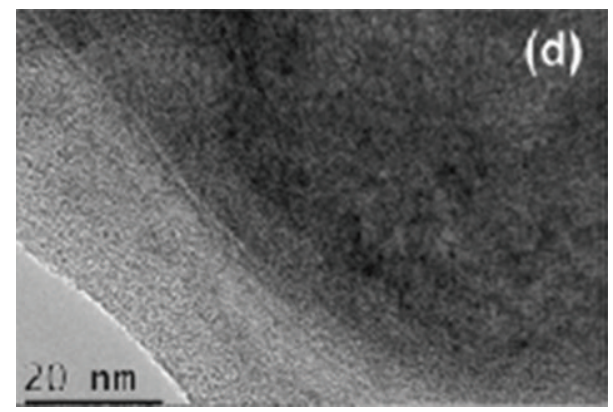

(d)

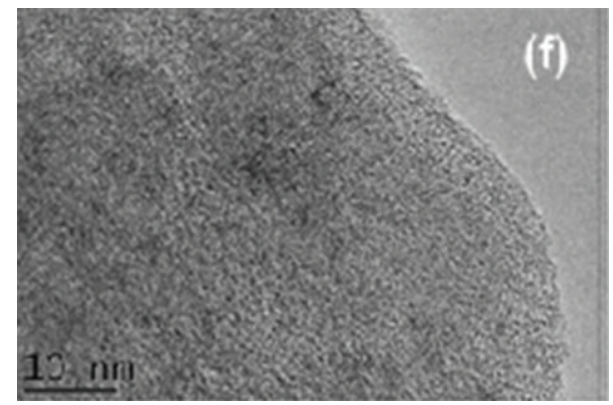

(f)

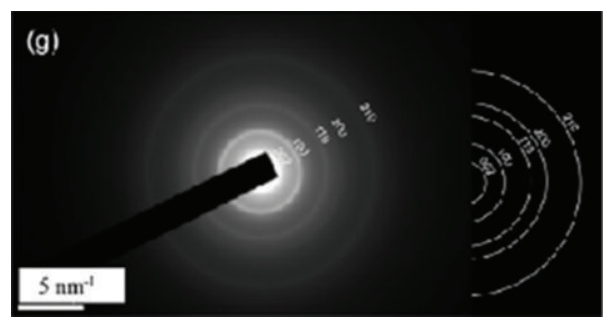

(g)

FIGURE 5: TEM micrographs of selected particles ((a)-(f)) and electron diffraction pattern (g).

formed on the quartz tube and at the top of the alumina injector has been underlined by Raman diffusion and TEM. Different populations coexist and differ by the agglomeration way. High interparticular porosity and low density is obtained when the individual particles are small, of around $50 \mathrm{~nm}$ size. At the top of the alumina injector, some grains exhibit a sintering-like structure probably formed by particles larger than $100 \mathrm{~nm}$. The different sizes of the particles forming the grains, 50 and $100 \mathrm{~nm}$, could be related either to different durations of formation or different temperatures. Whatever their morphology is, the samples do not contain nitrogen contrary to tholins.

As perspective of this research, we suggest to carry out a deepened analysis on the following aspects for the plasma formed around a Titan spacecraft in order to have precise information on the carbon formed. This paper and a previous one [5] show that solid carbon can be produced during the atmospheric entry of a probe into Titan atmosphere. Carbon synthesis is not observed at all for Mars-like atmosphere plasmas. Those results are in total agreement with those 

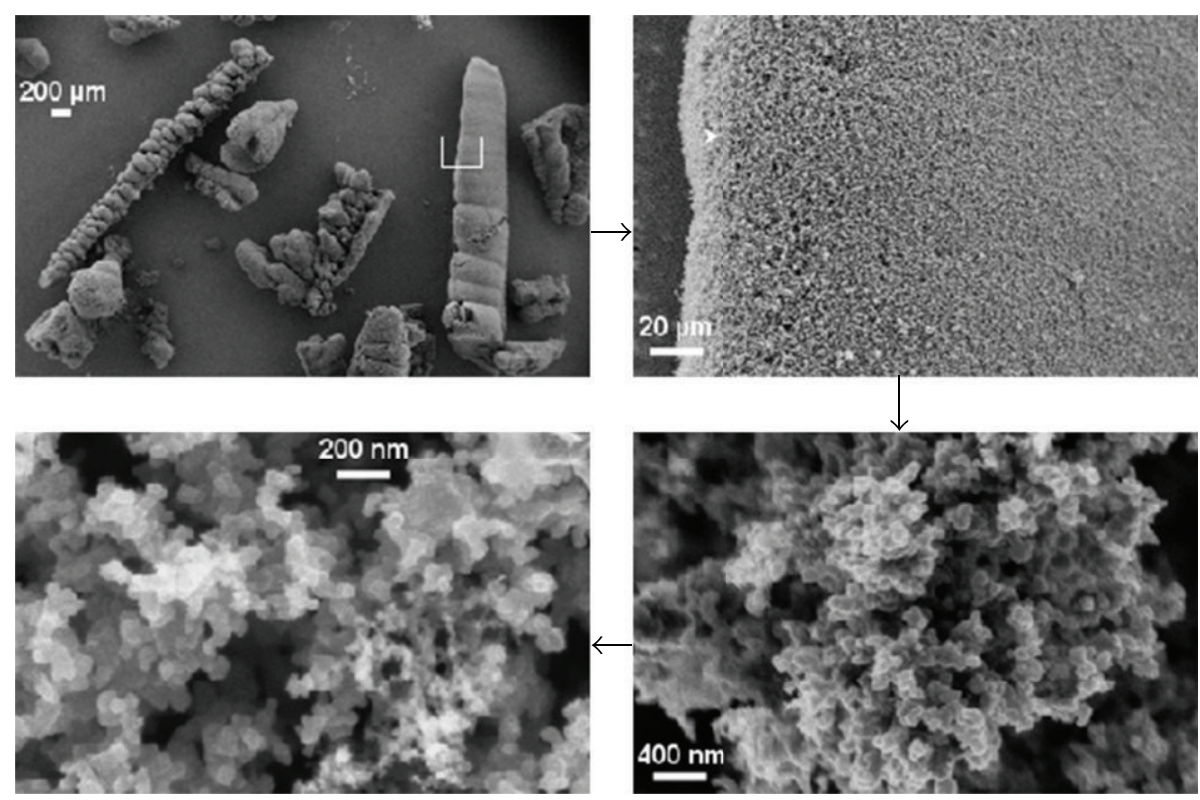

FIGURE 6: SEM observation of the porous-like structure.

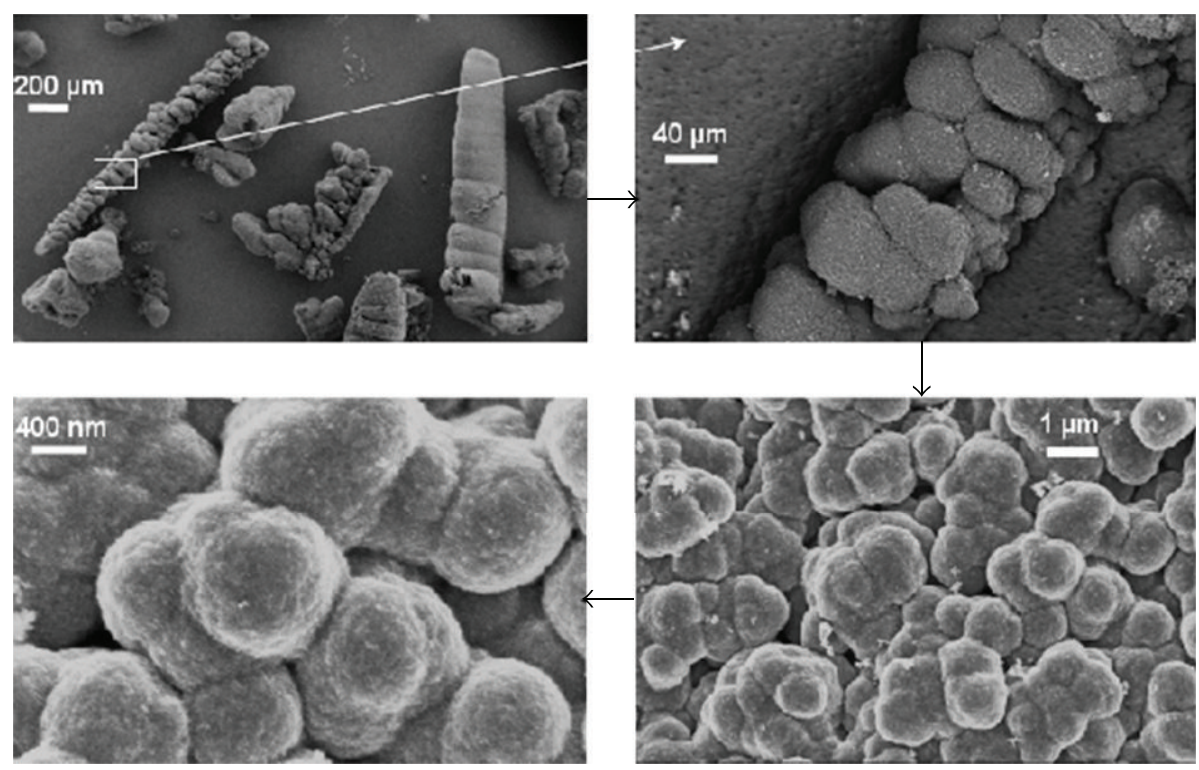

FIGURE 7: SEM observation of rough hair structure of carbon.

obtained using a shock tube and globally with thermodynamical calculations [5].

It is also known that natural photodissociation of methane into solid carbon occurs in Titan atmosphere because of solar radiations [22-24]. The presence of dust in the area of the probe impact with Titan's atmosphere can affect the plasma characteristics especially the radiation. It now seems necessary to study the effects of that kind of carbon on the entry conditions, as indeed;

(i) carbon can form a cladding layer and might favorize radiation absorption, leading to an overheating of the TPS; (ii) high temperature solid carbon might react with the TPS and spoil its protecting properties;

(iii) solid carbon could blind sensors.

It is essential to know more about the dust-radiation coupling for the optimization of thermal protection systems. A study of dust in volume should be carried out but should pass initially by a first detection and identification of composition using a dust laser plasma.

Nevertheless, this solid carbon production was achieved at earth atmospheric pressure. More specific experiments will have to be done at Titan entry pressure to evaluate the production rate of solid carbon in real conditions. 

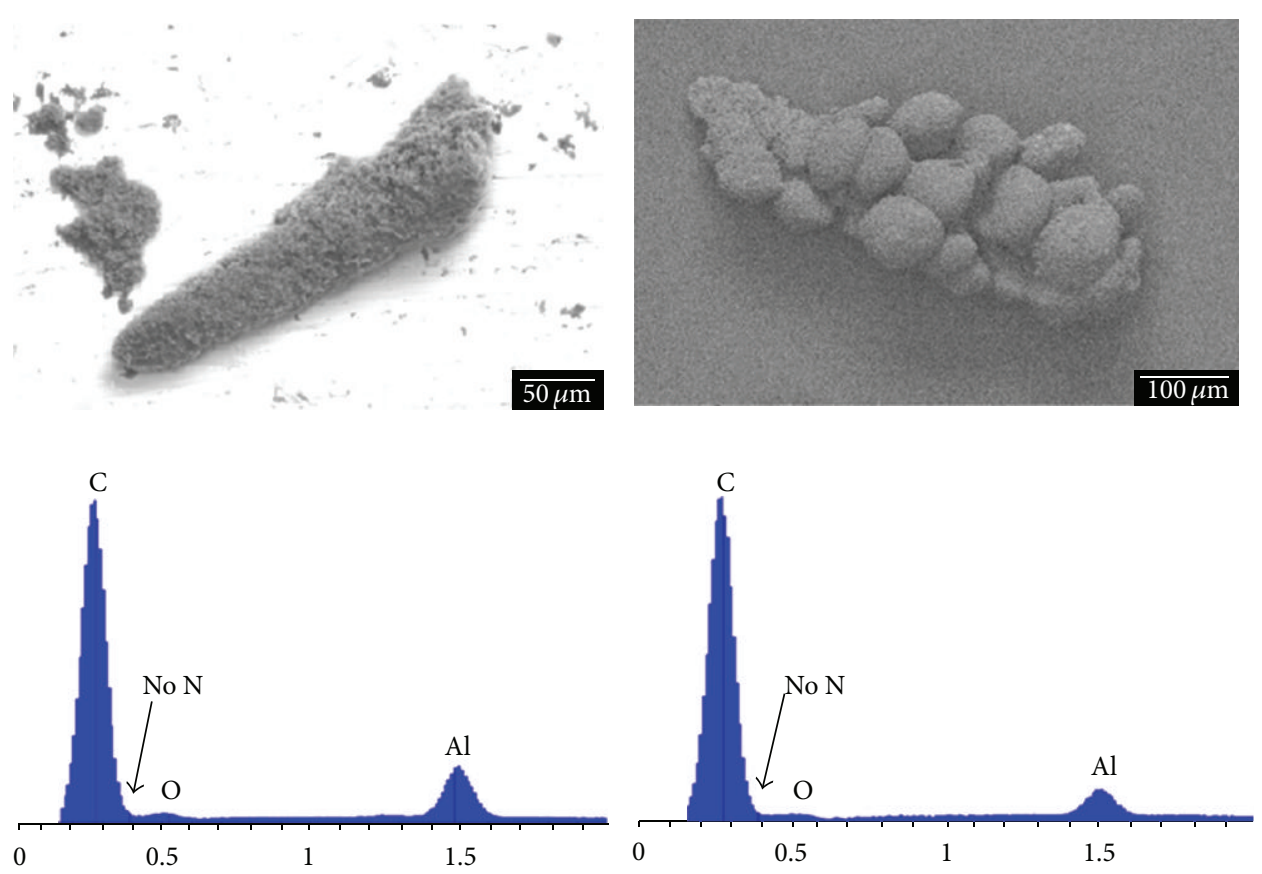

FIGURE 8: EDS analyses of both carbon structures.

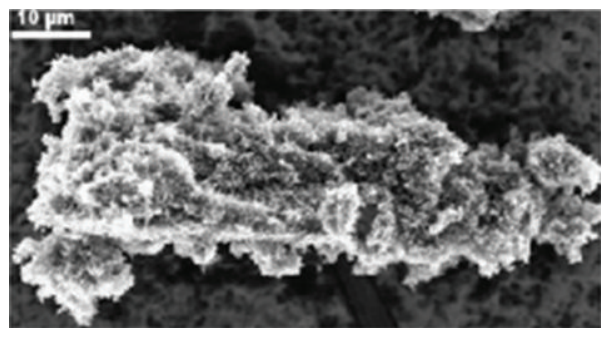

(a)

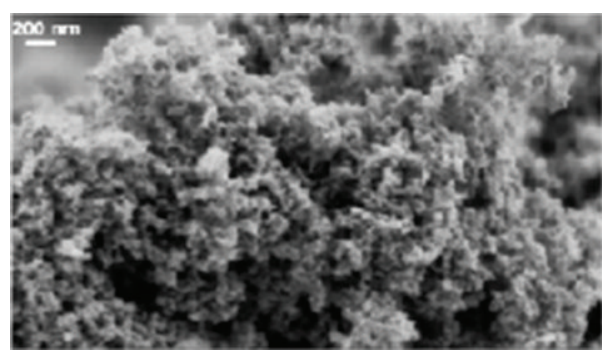

(c)

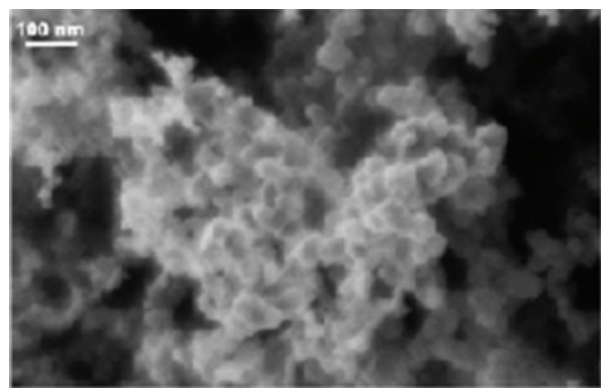

(e)

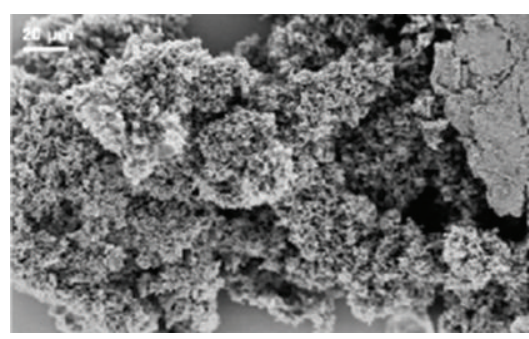

(b)

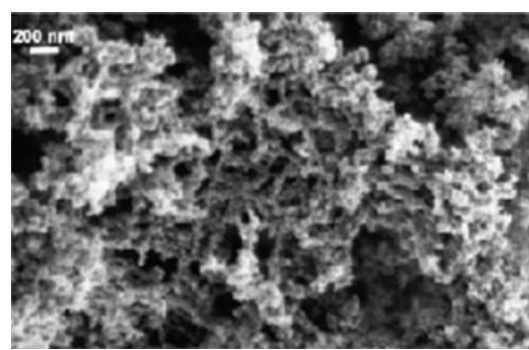

(d)

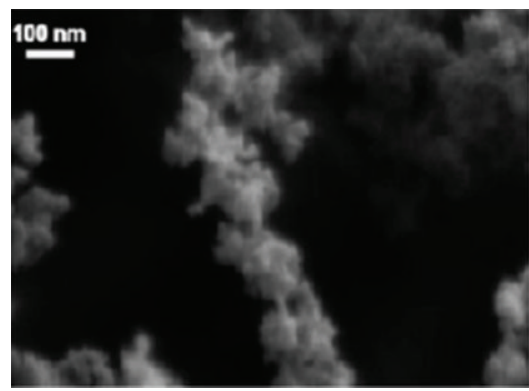

(f)

FigurE 9: TEM images of the samples formed on the top (left side) and on the bottom of the quartz tube (right). 


\section{References}

[1] G. Pulci, J. Tirillò, F. Marra, F. Fossati, C. Bartuli, and T. Valente, "Carbon-phenolic ablative materials for re-entry space vehicles: manufacturing and properties," Composites Part A, vol. 41, no. 10, pp. 1483-1490, 2010.

[2] J.-M. Bouilly, L. Dariol, and F. Leleu, "Ablative thermal protections for atmospheric entry. An overview of past missions and needs for future programmes," in Proceedings of the 5th European Workshop Thermal Protection Systems and Hot Structures, Noordwijk, The Netherlands, May 2006.

[3] P. Reynier, M. Bugel, and A. Smith, "Survey of European and major ISC facilities for supporting Mars and sample return mission aerothermodynamics and tests required for thermal protection system and dynamic stability," International Journal of Aerospace Engineering, vol. 2011, Article ID 937629, 18 pages, 2011.

[4] W. C. Mahaney, K. M. Hart, S. S. O’Reilly et al., "Coleoptera and microbe biomass in Antarctic Dry Valley paleosols adjacent to the Inland Ice: implications for Mars," Planetary and Space Science, vol. 60, no. 1, pp. 386-398, 2012.

[5] D. Vacher, M. Dudeck, P. André et al., "Radiation from an ICP plasma torch in the near-UV to near-IR spectral region for a Titan-type $\mathrm{N}_{2}-\mathrm{CH}_{4}$ mixture," Journal of Technical Physics, vol. 50, no. 3, pp. 213-231, 2009.

[6] S. Menecier, L. Legros, D. Vacher, N. Cerqueira, and P. André, "Temperatures of Titan and Mars-like plasmas measured by laser interferometry," Journal of Technical Physics, vol. 50, no. 3, pp. 199-212, 2009.

[7] C. Szopa, G. Cernogora, L. Boufendi, J. J. Correia, and P. Coll, "PAMPRE: a dusty plasma experiment for Titan's tholins production and study," Planetary and Space Science, vol. 54, no. 4, pp. 394-404, 2006.

[8] M.-J. Nguyen, F. Raulin, P. Coll et al., "Carbon isotopic enrichment in Titan's tholins? Implications for Titan's aerosols," Planetary and Space Science, vol. 55, no. 13, pp. 2010-2014, 2007.

[9] P. Coll, D. Coscia, N. Smith et al., "Experimental laboratory simulation of Titan's atmosphere: aerosols and gas phase," Planetary and Space Science, vol. 47, no. 10-11, pp. 1331-1340, 1999.

[10] C. D. Pintassilgo, J. Loureiro, G. Cernogora, and M. Touzeau, "Methane decomposition and active nitrogen in a $\mathrm{N}_{2}-\mathrm{CH}_{4}$ glow discharge at low pressures," Plasma Sources Science and Technology, vol. 8, no. 3, pp. 463-478, 1999.

[11] J. Pereira, V. Massereau-Guilbaud, I. Géraud-Grenier, and A. Plain, " $\mathrm{CH}$ and $\mathrm{CN}$ radical contribution in the particle formation generated in a radio-frequency $\mathrm{CH}_{4} / \mathrm{N}_{2}$ plasma," Plasma Processes and Polymers, vol. 2, no. 8, pp. 633-640, 2005.

[12] J. Pereira, I. Géraud-Grenier, V. Massereau-Guilbaud, and A. Plain, "Characterization of hydrogenated amorphous carbon nitride particles and coatings obtained in a $\mathrm{CH}_{4} / \mathrm{N}_{2}$ radiofrequency discharge," Thin Solid Films, vol. 482, no. 1-2, pp. 226231, 2005.

[13] R. Pristavita, N.-Y. Mendoza-Gonzalez, J.-L. Meunier, and D. Berk, "Carbon blacks produced by thermal plasma: the influence of the reactor geometry on the product morphology," Plasma Chemistry and Plasma Processing, vol. 30, no. 2, pp. 267279, 2010.

[14] J. Gonzalez-Aguilar, M. Moreno, and L. Fulcheri, "Carbon nanostructures production by gas-phase plasma processes at atmospheric pressure," Journal of Physics D, vol. 40, no. 8, article S16, pp. 2361-2374, 2007.
[15] F. Fabry, G. Flamant, and L. Fulcheri, "Carbon black processing by thermal plasma: analysis of the particle formation mechanism," Chemical Engineering Science, vol. 56, no. 6, pp. 21232132, 2001.

[16] J. Robertson, "Diamond-like amorphous carbon," Materials Science and Engineering, vol. 37, no. 4-6, pp. 129-281, 2002.

[17] S. Urbonaite, L. Hälldahl, and G. Svensson, "Raman spectroscopy studies of carbide derived carbons," Carbon, vol. 46, no. 14, pp. 1942-1947, 2008.

[18] T. F. Tuinstra and K. J. Koenig, "Raman spectrum of graphite," Journal of Chemical Physics, vol. 53, no. 3, pp. 1126-1130, 1970.

[19] A. C. Ferrari and J. Robertson, "Interpretation of Raman spectra of disordered and amorphous carbon," Physical Review B, vol. 61, no. 20, pp. 14095-14107, 2000.

[20] A. C. Ferrariand and J. Robertson, "Resonant Raman spectroscopy of disordered, amorphous, and diamond like carbon," Physical Review B, vol. 64, no. 7, Article ID 075414, 2001.

[21] J. B. Donnet, R. C. Bansal, and M. J. Wang, Carbon Black Science and Technology, Marcel Dekker, New York, NY, USA, 2nd edition, 1993.

[22] E. Sciamma-O’Brien, P.-R. Dahoo, E. Hadamcik et al., "Optical constants from $370 \mathrm{~nm}$ to $900 \mathrm{~nm}$ of Titan tholins produced in a low pressure RF plasma discharge," Icarus, vol. 218, no. 1, pp. 353-363, 2012.

[23] J. H. Waite Jr., D. T. Young, T. E. Cravens et al., "Planetary science: the process of tholin formation in Titan's upper atmosphere," Science, vol. 316, no. 5826, pp. 870-875, 2007.

[24] N. Carrasco, T. Gautier, E.-T. Es-sebbar, P. Pernot, and G. Cernogora, "Volatile products controlling Titan's tholins production," Icarus, vol. 219, no. 1, pp. 230-240, 2012. 

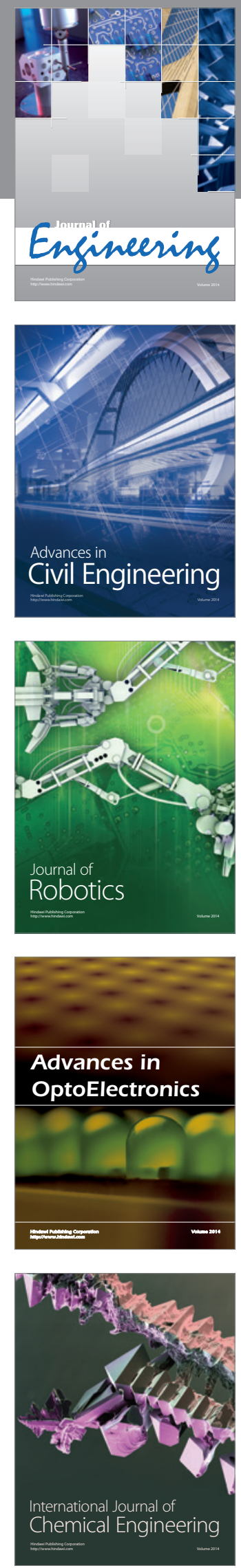

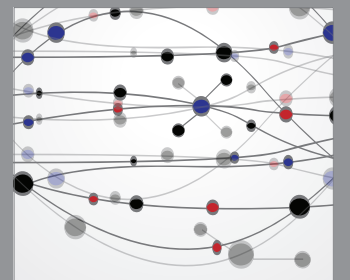

The Scientific World Journal
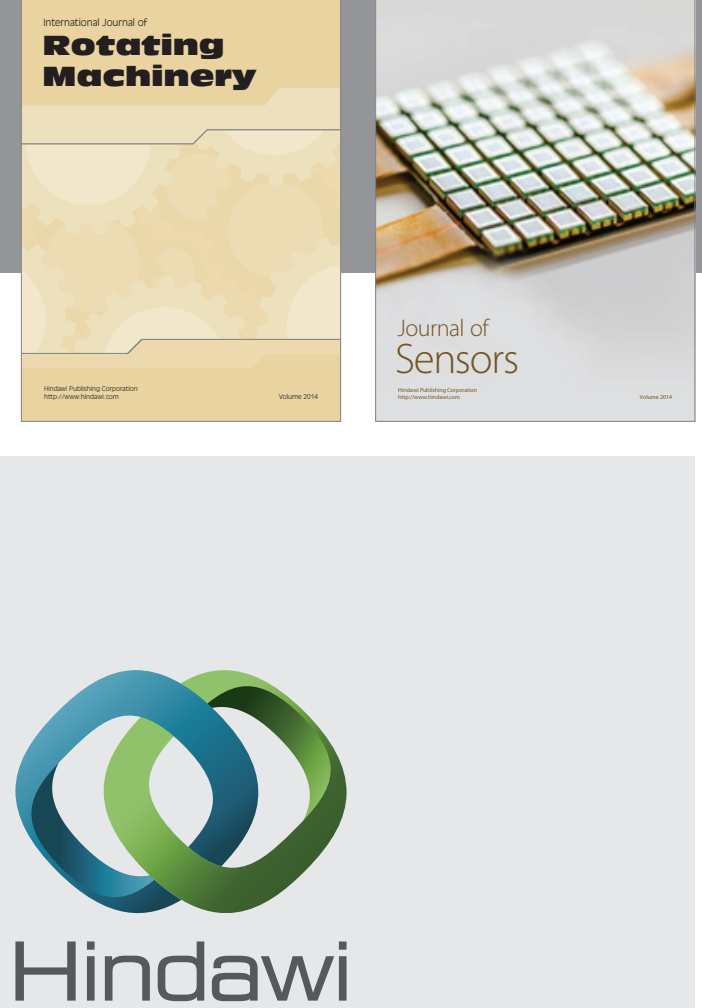

Submit your manuscripts at http://www.hindawi.com
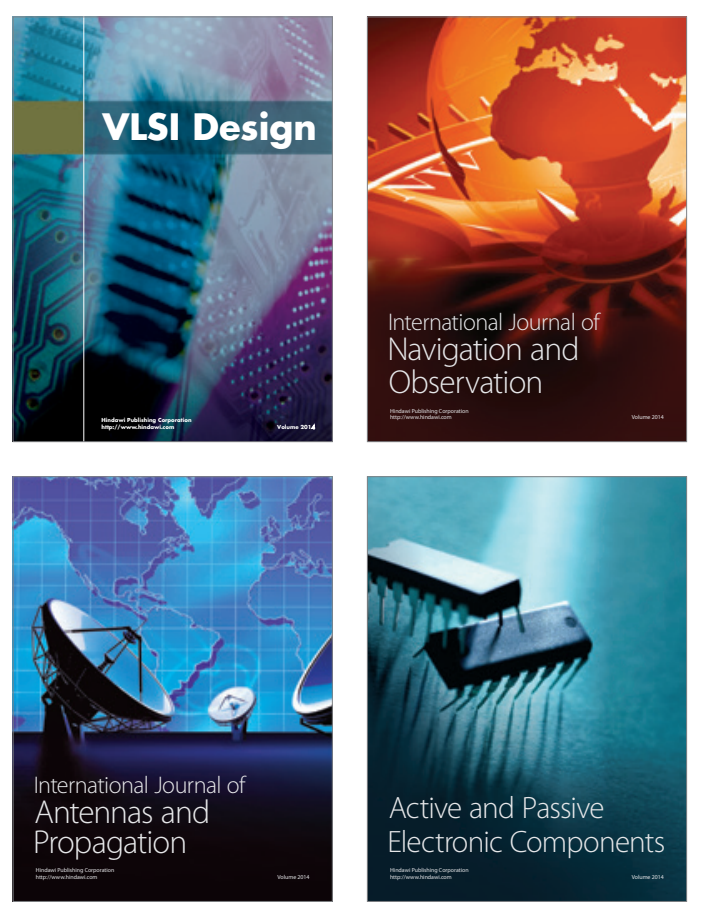
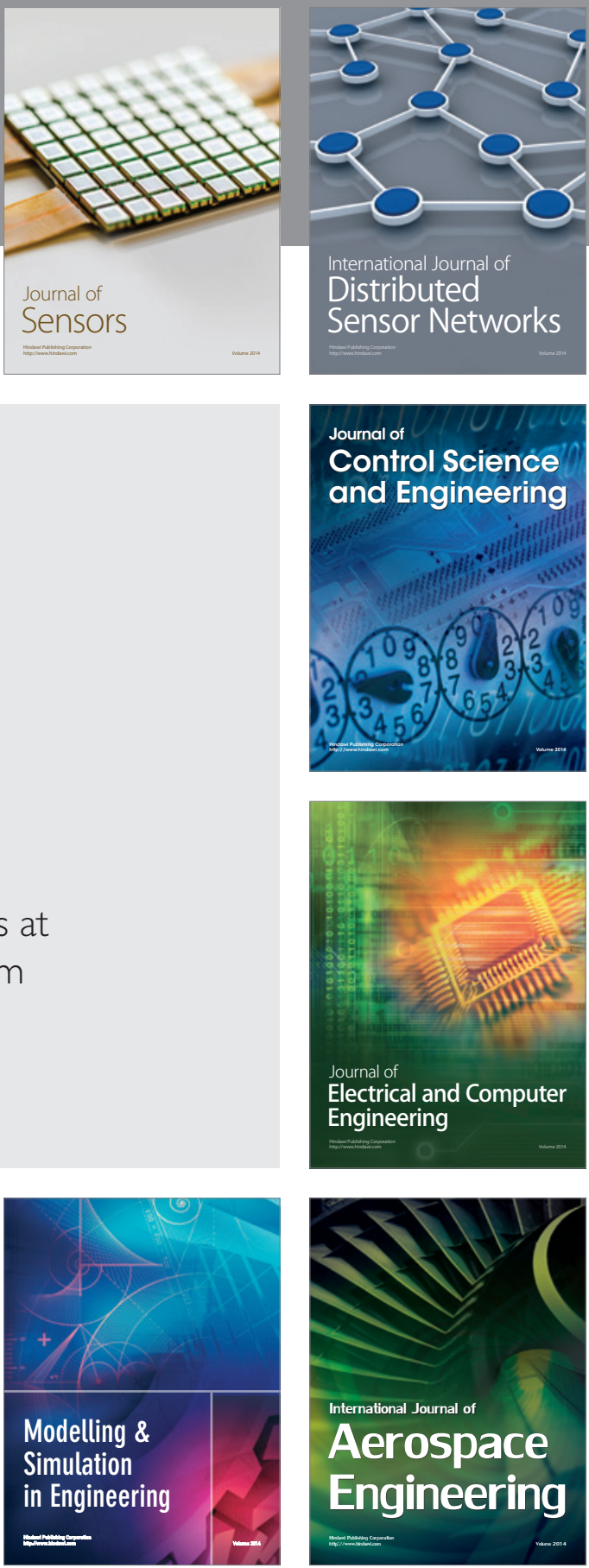

Journal of

Control Science

and Engineering
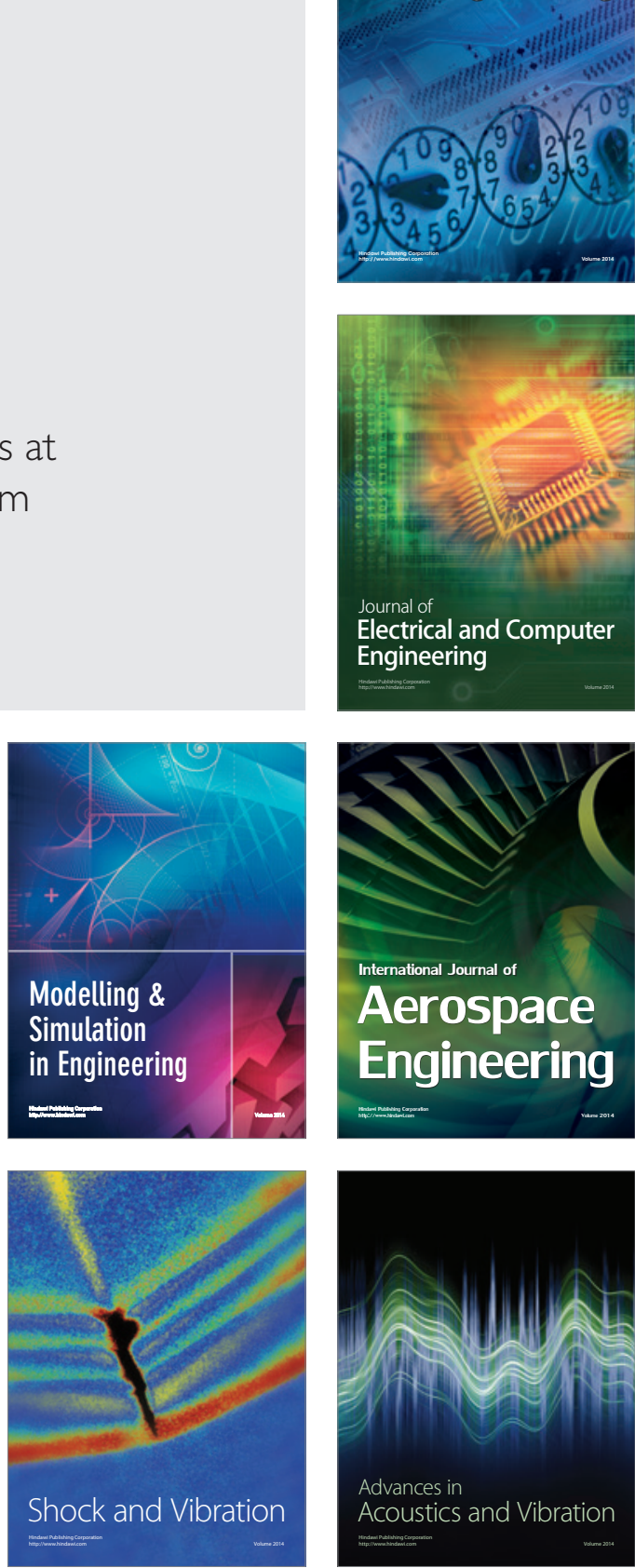